\title{
Educar desde el corazón para la transformación del mundo
}

\section{La Inteligencia Emocional y la Educación Popular}

\author{
Gabriela P. Serrano P. ${ }^{16}$ \\ gabriela.serrano@feyalegria.org.ec
}

Artículo recibido en abril 2018 y aceptado en mayo 2018

\section{Resumen}

La Educación Popular es esencialmente transformadora, y dicha transformación atañe desde lo humano a lo social. De allí que sus prácticas innovadoras siempre han de estar impregnadas de la calidez y la calidad que busca un mejor presente y un mañana cada vez más justo. La Educación Popular construye una pedagogía donde no solo es importante las capacidades intelectuales, sino también la construcción de la personalidad de un ser humano integral, pleno y transformador. En este sentido la inteligencia emocional y la educación popular se entrelazan perfectamente como claves para la transformación educativa y social. La presencia de los principios de la educación popular asociados a la educación del ser y las emociones genera en los centros educativos espacios para un desarrollo integral.

Palabras Claves: Educación Popular, Inteligencia Emocional, Formación Integral del Ser, Transformación Educativa y Social.

\section{Abstrac}

Popular Education is essentially transformative, and so far, as concern such transformation, this ranges from the human level to the social one. Thereof, its innovative practices must always work towards warmth and

16 Máster en Orientación Psicológica Educativa por la Universidad Católica del Táchira (UCAT) Venezuela. Licenciada en Educación Integral (UCAT). Diplomada en Psicología Infantil, Especialista en Terapia Familiar e infantil. Estudios en innovación educativa y coaching Positivista. Experiencia en consultoría de la Asociación Venezolana de Educación Católica (AVEC), Maestra de aula, docente universitario y Asesora Psicológica. Ponente y conferencista en temas psicoeducativos. Actualmente Coordinadora Nacional de Educación General Básica Fe y Alegría Ecuador. 
quality that seek and deserve a better present and a fair future. Popular Education builds a pedagogy where not only intellectual abilities are important, but also the full development of the personality of an integral and transformational human being. In this regard, emotional intelligence and popular education are perfectly interconnected as keys for educational and social transformation. The presence of the principles of popular education associated with the education of human beings and their emotions generates opportunities for integral development in educational centers.

Key Words: Popular Education, Emotional Intelligence, Integral Human Formation, Educational and Social Transformation.

\section{Introducción}

La educación es sinónimo de un mejor futuro para una nación, de mayor equidad, de mejores oportunidades, de solidaridad y de crecimiento, y para que esta realidad sea factible, la educación debe ser de alta calidad, debe ser justa, congruente a las necesidades de la sociedad actual y a los nuevos retos que se generan en estos tiempos. Siendo por encima de todo profundamente humana.

En este sentido, la formación de los niños, niñas y adolescentes debe apuntar a una visión actualizada a los retos del presente y el devenir del futuro, donde no solo es importante la capacidad memorística, sino también la resolución de conflictos y la construcción de la personalidad. Es en este punto, la Educación Popular genera elementos indispensables para el fortalecimiento de los espacios de aprendizaje, posibilitando una convivencia más armónica al tiempo que se potencian las habilidades del ser humano.

El objetivo principal del presente artículo es: 1. Presentar la inteligencia emocional y la educación popular como claves para la transformación educativa y social. Los objetivos específicos son: 1. Reseñar las bases de la inteligencia emocional en la práctica educativa 2. Identificar los principios de la educación popular asociados a la educación del ser y las emociones 3. Explicar la importancia de la inteligencia emocional en la educación popular y su articulación. 
Las conclusiones convergen en razón al tema central de la revista: "Educación Popular". Por tal, se espera que las claves y reflexiones emanadas del presente artículo contribuyan a fortalecer la práctica pedagógica de nuestros centros educativos.

\section{Educar desde el corazón en Fe y Alegría}

(...) Usted formó mi corazón para la libertad, para la justicia, para lo grande, para lo hermoso (...) No puede usted figurarse cuán hondamente se han grabado en mi corazón las lecciones que usted me ha dado; no he podido jamás borrar siquiera una coma de las grandes sentencias que usted me ha regalado (...) ${ }^{17}$

\section{Palabras del Libertador Simón Bolívar a Simón Rodríguez desde Perú.}

La Educación Popular es por esencia transformadora, proponiéndose una transformación que nace desde la persona, para transformar así el todo. En Fe y Alegría como Movimiento de Educación Popular, Integral, de Promoción Social, Acción Pública, y Espiritualidad Transformadora, es inevitable partir del corazón, nacer desde lo humano.

En palabras de Simón Bolívar a su gran maestro Simón Rodríguez, la educación no debe ser solo aquella que se refleja en el intelecto, sino también la que se plasma en el corazón; una educación que forma para lo grande, para lo hermoso y para el futuro, una educación que transforma el ser y el vivir de los educandos, de los educadores, de las familias y los centros, una educación que parte del contexto y que le transforma.

A razón de ello, formar para lo complejo y para el futuro, requiere de la adecuación de estrategias complejas y actualizadas, comprendiendo y desafiando los retos que supone la educación actual en el mundo. De allí el pensamiento de Edgar Morín (2004) ${ }^{18}$ : "Los analfabetos del siglo XXI no serán los que no sepan leer ni escribir, sino

17 Simón Bolívar. 1824. Palabras del Libertador a Simón Rodríguez desde Perú. P. 27.

18 Edgar Morín. 2004. Transformando la Educación. Tomado de Itinerario Red Qualitas. P.88. 
los que no puedan aprender, desaprender y reaprender." (p. 88). Este aprender es amplio y necesario, estando cada vez mas lejos del mero saber catedrático y profundizándose más en la persona, en su ser, su sentir, su conocer, su hacer, su convivir, y sus competencias y habilidades vistas de una manera integral. Actualmente esta argumentado desde diversos estudios y enfoques teóricos la importancia de la formación de habilidades para la vida y la formación del ser.

En este sentido, la esencia de Fe y Alegría permite generar espacios de calidez y calidad, que parten desde lo humano y transforman todas las áreas del quehacer educativo. No es casualidad que el sistema metodológico de Fe y Alegría sea el CORDIS ${ }^{19}$, el cual además de ser la metodología que guía a Fe y Alegría tiene su valiosa connotación expresada en el Horizonte Pedagógico Pastoral (2016) ${ }^{20}$ :

La palabra que resulta de las iniciales de este sistema es CORDIS que remite a la raíz latina de la palabra CORAZÓN, inmediatamente nos dirige hacia el símbolo por excelencia de Fe y Alegría y a la búsqueda de la pedagogía del amor como centro fundamental del esfuerzo que hacemos por estar cercanos a quienes son parte de los procesos educativos. (p. 96)

(Federación Internacional. Fe y Alegría, 2002. Tomado del Horizonte Pedagógico Pastoral Fe y Alegría Ecuador).

De allí que, guiados desde el CORDIS, con todo lo que ello connota, la educación que se piensa, vive, siente y se construye en Fe y Alegría parte desde el corazón, siendo este misericordioso (La palabra misericordia viene del latín formado de miser (miserable, desdichado), cordis (corazón) y el sufijo -ia. Refiriendo a la capacidad de sentir la desdicha de los demás). Y un corazón que recuerda (la palabra «recordar» viene del latín "recordari ", formado de re "de nuevo" y cordis, recordar quiere decir mucho más que tener a alguien presente en la memoria, significa «volver a pasar por el corazón").

19 Contextualización, Revalorización de saberes y experiencias, Diálogo de saberes, Innovación Transformadora, Sistematización y Socialización.

20 Fe y Alegría Ecuador. 2016. Horizonte Pedagógico Pastoral. P. 96 
Este significado deja ampliamente evidente lo que es el ser humano en su esencia para la educación popular, generando de esta manera en los centros educativos un espacio por excelencia para las emociones, para el convivir, el ser, el hacer, el crecer, conocer, el saber y el convivir.

La educación popular y su pedagogía siempre han planteado en su dinámica la dimensión psico afectiva, en este particular y referente a la pedagogía del amor Antonio Pérez Esclarín (2004) ${ }^{21}$ indica:

Se trata de respetar y cultivar los procesos psicológicos, emocionales, y afectivos de cada persona, de modo que se pueda crecer armónicamente y desarrollar las competencias necesarias para que pueda ejercer su afectividad, sexualidad y libertad en un modo maduro y responsable. Competencias que le lleven a desarrollar su identidad personal, familiar y social, que le ayuden a conocerse, quererse y emprender el camino de su propia realización con los demás. Competencias para no agredir ni física ni verbal ni psicológicamente al otro, que favorezcan el autoestima y autonomía personal, el respeto, la capacidad de relacionarse y comunicarse positivamente con los demás (familia, compañeros, comunidad). El desarrollo de la voluntad y el carácter, la toma de decisiones, las relaciones de género, el compromiso personal y social, la autonomía y la libertad responsable. (p.48)

La pedagogía del amor forma parte esencial de la Educación Popular, no se puede enseñar solo desde lo cognitivo o intelectual, se forma al ser en plenitud de todas sus aristas y dimensiones. Negar las emociones es negar lo humano, no se puede realmente educar si no se consideran las emociones, y más allá de considerar, no se podría formar integralmente sino se forma desde el corazón.

\section{La Inteligencia Emocional en la Práctica Educativa}

Somos mensajeros de la fe y al mismo tiempo mensajeros de la alegría, Mensajeros de la Fe y Maestros de la Alegría. Debemos

21 Antonio Pérez Esclarín. 2004 colección programa internacional de formación de Educadores populares. La educación popular y su pedagogía. Editorial Federación Internacional de Fe Y Alegría. Venezuela. p. 48 
por lo tanto aspirar a ser pedagogos en la Educación de la Fe y pedagogos de la Alegría...Dos vuelos espirituales tan hermosos y radiantes que son capaces de enamorar una vocación. Dos poderes y dos dones de Dios que son capaces de transformar el mundo.

(P. José María Vélaz S.J )22

En la educación actual se hace cada vez más indispensable una práctica que pondere en su justa medida lo emocional. En este sentido son diversos los avances en las teorías psicoeducativas como los son las de H. Gardner, D. Goleman, entre otras, las cuales han avanzado ampliamente en la incidencia que tiene lo emocional en las prácticas pedagógicas. La inteligencia emocional y las estrategias que de allí se desglosan se configuran como bases sobre las cuales se puede edificar la nueva educación, una que se adapte a los tiempos actuales, y se reconfigure en virtud de las exigencias de los tiempos venideros.

Para adentrarse en la inteligencia emocional, es oportuno realizar un breve recorrido histórico en sus antecedentes y edificación. Así como en sus principios y fundamentos, para poder de esta manera, llegar a su aplicación práctica en el aula y en la vida diaria.

\section{Breve recorrido histórico de la inteligencia emocional}

La inteligencia emocional ha evolucionado desde hace más de 2000 años a la connotación que tiene en la actualidad, luego de diversos aportes de estudiosos, y de valiosas teorías, entre ellas las más influyentes son las de los autores: Aristóteles (-384 - 322), Santo Tomas de Aquino ( 1224 - 1274), Rene Descartes (1596 - 1650), Skinner ( 1904 - 1990), Scott (1927 - 1986), entre otros, cada uno de ellos desde sus teorías y filosofías versaron referente a las emociones y las aproximaciones a lo que hoy se conoce como inteligencia emocional.

En cuanto a los teóricos más recientes y trascendentes se encuentran: Roberth Plutchik (1927 - 2006) con su teoría del circulo

22 Lazcano, J. s.j. 2005. Palabras de Fe y Alegría. Citas inspiradoras del Padre José María Vélaz. Caracas: Federación Internacional Fe y Alegría. 
cromático de las emociones y su combinación; a Salovey (1958) y Mayer quienes acuñan por primera vez el término inteligencia emocional. A partir de estos autores, y con la participación de Howard Gardner y Daniel Goleman se da a conocer a nivel mundial la teoría de la inteligencia emocional, visualizándose que las emociones se pueden percibir como ideas adaptativas que podrían conducir a la transformación de interacción personal y social en una experiencia enriquecedora.

\section{Emociones}

La inteligencia emocional tiene su base en las emociones, y en el fortalecimiento idóneo de las mismas, para un uso adecuado y potenciación de la personalidad por medio de un equilibrio emocional. En este sentido, "Las emociones conducen a la acción, son sistemas poderosos que nos permiten responder al entorno, dirigen la conciencia, le dan sentido a la existencia y mueven las personas al cambio" Jazmín Sambrano $(2014)^{23}$. De allí que, la inteligencia emocional se focalizar en el discernimiento de las mismas buscando consecuentemente una alfabetización emocional. (p.14)

La misma palabra emoción, en su significado etimológico (emotio que deriva del latín movere) indica movimiento, y con el prefijo e, indicaría movimiento hacia. Lo cual sugiere que toda emoción presenta una tendencia a una actuación o movimiento. Las emociones tienen su componente psicológico, fisiológico y social, de allí la importancia de educar en la emoción y educar la emocionalidad. Dicha formación, requiere una instrucción previa del educador, en virtud de que este domine el conocimiento necesario y pueda hacer uso correcto de las diversas estrategias que proporciona la inteligencia emocional.

\section{Ocho emociones importantes y las consecuencias que genera:}

1. Ira

2. Tristeza

3. Miedo

4. Alegría

23 Sambrano, J. (2014) Inteligencia Emocional. Guía práctica para alfabetizar nuestras emociones. Editorial ALFA. Venezuela. . (p.14) 


\section{Sorpresa \\ 6. Amor \\ 7. Disgusto \\ 8. Vergüenza}

En función a la teoría o autor que se visualice se van a encontrar diversas categorizaciones de las emociones, no obstante, estas 8 emociones básicas mencionadas por Sambrano, J. ${ }^{24}$ son fundamentales de articular para la inteligencia emocional.

Estas 8 emociones han de ser conocidas y manejadas eficazmente por el educador, haciendo de su práctica educativa más cónsona con una formación integral y humana. Este conocimiento va a tener principalmente dos dimensiones, una a nivel personal sobre su propia práctica y experiencia, y otro nivel profesional y su aplicabilidad en el entorno educativo.

Al respecto del trabajo con las emociones Gómez (2013) ${ }^{25}$ brinda el siguiente aporte:

El cultivo de las denominadas emociones positivas, estipulando su desarrollo, a la vez que la disciplinada acción de encauzar las emociones negativas, es una herramienta igualmente indispensable. La ira, el miedo, la tristeza, el odio, el resentimiento, la envidia, el orgullo, entre otras, son estados mentales que generan estados neurofisiológicos enérgicos que obstaculizan, entraban y dificultan el proceso en el camino de la expansión de la conciencia. Por el contrario, la paz, la alegría, la serenidad, el coraje, la prudencia, la actitud amorosa hacia si mismo y los demás, la plenitud, la tolerancia, la compasión, etc., generan cambios neuroquímicos, neuro simpáticos, y enérgicos que facilitan la emergencia del nuevo estado. (p.203)

24 Sambrano, J. (2014) Inteligencia Emocional. Guía práctica para alfabetizar nuestras emociones. Editorial ALFA. Venezuela. (p.16)

25 Héctor G. Gómez, G. 2013 Un mapa en el laberinto. La felicidad es un estado mental y puede ser aprendido. Editorial Singularidad. P. 203 


\section{Componentes de la Inteligencia Emocional}

Para fomentar la inteligencia emocional como parte indisoluble en la vida personal, han de estimularse y solidificarse ciertos componentes.

$\checkmark$ Aptitudes Personales: referidas a el autoconocimiento, la autorregulación, el afán de triunfo, el compromiso, la iniciativa y el optimismo.

$\checkmark$ Aptitudes Sociales: Vinculadas con la influencia, la comunicación, el manejo de conflictos, el liderazgo, la canalización de cambios, entablar vínculos, la cooperación y el trabajo en equipo.

$\checkmark$ La inteligencia intrapersonal: relacionada al conocimiento de sí mismo, sus fortalezas y debilidades.

$\checkmark$ La inteligencia interpersonal: la capacidad para percibir y establecer diferencias entre los distintos estados de ánimo de otras personas.

Partiendo desde estos componentes esenciales de la inteligencia emocional, es válido argumentar como gracias a la educación en inteligencia emocional, se puede consolidar cambios profundos con miras a una transformación real, que parte de la persona e incide en el contexto. Una formación que carezca de estos componentes escasamente podría llamarse formación integral, no se puede ser ajeno a esta realidad tan sonora como lo es la necesidad de formar al ser desde una visión integral que genere espacios para el desarrollo emocional.

\section{Importancia de la inteligencia emocional en la educación popular y su articulación}

La educación popular se propone transformar los contextos, en especial los más vulnerables, con visión en generar una incidencia a nivel social con un impacto real en las comunidades. En este particular, la transformación cada vez se hace mas imperiosa y supone mayores retos.

Al respecto, la educación además de ser una labor excelsa y 
única, está cargada de grandes responsabilidades y compromisos. Tal como indica el educador y filósofo Edgar Morín (1999) ${ }^{26}$ refiriéndose a la importancia de transformar la educación:

La educación es "la fuerza del futuro" ... Constituye uno de los instrumentos más poderosos para realizar el cambio. Uno de los desafíos más difíciles será el de modificar nuestro pensamiento de manera que enfrente la complejidad creciente, la rapidez de los cambios y lo imprevisible que caracteriza nuestro mundo. Debemos reconsiderar la organización del conocimiento. Para ello debemos derribar las barreras tradicionales entre las disciplinas y concebir la manera de volver a unir lo que hasta ahora ha estado separado. Debemos reformular nuestras políticas y programas educativos. Al realizar estas reformas es necesario mantener la mirada fija hacia el largo plazo, hacia el mundo de las generaciones futuras frente a las cuales tenemos una enorme responsabilidad. (p.7)

Ciertamente, la educación posee en si un tesoro incalculable, pero también requiere ser transformada para alcanzar sus potencialidades. Esta transformación solo es posible, mediante la responsabilidad compartida de todos los actores del hecho educativo (Estudiantes, Padres, Madres, Representantes, Educadores, Personal Institucional, Comunidad, El Estado)

La educación es un proceso multifactorial, en el cual, se conjugan una serie de elementos que deben actuar en el mismo sentido y en sinergia, para poder lograr un proceso educativo congruente $y$ fortalecedor.

De allí que, producto de las experiencias de las prácticas pedagógicas de Fe y Alegría Ecuador, se han generado espacios donde las estrategias metodológicas van nutriéndose. El sistema metodológico de Fe y Alegría CORDIS, propone y brinda un espacio vital para la Innovación Transformadora, permitiendo y estimulando en sus prácticas cambios sustanciales que generen transformaciones significativas en todo el proceso educativo.

26 Edgar Morín (1999) Los siete saberes necesarios para la educación del futuro. UNESCO Francia p. 7 
Por consiguiente, Fe y Alegría Ecuador desde largo tiempo ha generado espacios de innovación transformadora y de profundización del ser y de lo emocional, como lo son y lo han sido las formaciones para la familia, para los colaboradores de Fe y Alegría, para los estudiantes y todos los actores del movimiento, formaciones ignacianas, formaciones pedagógicas como lo son las Estrategias Metodológicas de Lectura y Expresión y Pensamiento Lógico con énfasis en las matemáticas, y más recientemente las formaciones en el proyecto de innovación con las hermanas de Nazareth, donde se han brindado valiosos espacios para la trasformación de las prácticas pedagógicas. Asimismo, Los campamentos ecuatorianos de Fe y Alegría (CEFA), El Movimiento Infantil de Fe y Alegría (MIFA) y la Pastoral en los centros han brindado espacios para el desarrollo emocional. Todo enmarcado en un Sistema de Mejora de la Calidad que impulsa una transformación desde lo interno.

Todo este transitar que ha realizado Fe y Alegría Ecuador, lo hace un terreno fértil para prácticas innovadoras, en las cuales los espacios para el desarrollo personal en un sentido holístico, están cada vez más presentes. De allí que, la inteligencia emocional ha estado tanto implícita como explicita en varias de estas iniciativas. En la actualidad, el proyecto de innovación brinda herramientas específicas desde las inteligencias múltiples para el desarrollo de la inteligencia intrapersonal e interpersonal, siendo ambas componentes fundamentales de la inteligencia emocional.

Se ve, por ende, una articulación clara y longitudinal entre la educación popular y la inteligencia emocional. Donde la inteligencia emocional fluye y beneficia indiscutiblemente las prácticas pedagógicas y pastorales de los centros educativos.

\section{Como trabajar la inteligencia emocional y educar la emocionalidad}

Existen diversos modelos para desarrollar las competencias emocionales, la Universidad de Barcelona (España) propone el modelo GROP ( Grup de reserca en Orientación Psicopedagógica), según el cual se contemplan 5 grandes competencias: 
1. Conciencia emocional

2. Regulación Emocional

3. Autonomía emocional

4. Competencia Social

5. Habilidades de vida para el bienestar.

Este modelo para desarrollar las competencias emocionales puede articularse con los diversos espacios que se generan en la Revalorización de Experiencias y Saberes, en el Dialogo de Saberes, en la Innovación Transformadora, y en el día a día. Está en el tino, la creatividad y el interés del educador para concebir y consolidar estos espacios armónicos donde se estimulen las competencias emocionales.

\section{La inteligencia emocional, el estudiante y el docente}

La inteligencia emocional es clave para los procesos transformacionales del área educativa y social. En este particular, es indispensable que los educadores integren y fortalezcan desde el aula las estrategias más optimizadas para que los estudiantes reconozcan e incorporen a su rutina los elementos esenciales de la inteligencia emocional. De esta manera, al incorporarse de forma continua y sistematizada la inteligencia emocional en el aula, el estudiante internalizará en su proceder la misma, generando un ambiente de armonía, convivencia y aprendizajes más significativos.

Al fortalecer la Inteligencia Emocional se potenciará en el estudiante los siguientes rasgos:

\section{Características de las personas con Inteligencia Emocional}

Tomado de Maestro J (2009) $)^{27}$ :

27 Maestro J (2009): Regálate liderazgo, una estrategia para desarrollar los talentos emocionales del Líder. Editorial Porfit. P 29 
1. Posee una autoestima adecuada, se valora, se conoce y se autoafirma como ser único.

2. Confía en sus intuiciones y valoraciones.

3. Sabe lo que está sintiendo y lo puede expresar con claridad, tanto con su cuerpo como con sus palabras e identifica los sentimientos propios.

4. Utiliza el pasado como elemento de aprendizaje para futuras acciones.

5. Está orientado a la relación, tanto consigo mismo, como con los demás, participa activamente en las relaciones.

6. Es una persona positiva

7. Sabe dar y recibir.

8. Entiende los sentimientos de los otros (empatía)

9. Es capaz de expresar tanto las emociones negativas como las positivas.

10. Es capaz de controlar y regular sus emociones.

11. Sabe superar obstáculos y frustraciones.

12. Encuentra equilibrio entre exigencia y tolerancia.

13. Siente entusiasmo, motivación y energía para lograr sus objetivos

\section{Rol del estudiante}

El rol del estudiante es protagónico, los estudiantes son el eje central del proceso educativo, son la razón de ser y en virtud de quienes debemos enfocar los más loables esfuerzos. En este punto, la inteligencia 
emocional, estimula un estudiante protagónico del aprendizaje, co creador del hecho educativo, seguro de sí mismo, que conoce sus emociones y sabe entender, valorar y respetar las de los demás.

En el sentido emocional, también se ha ido transitando progresivamente de la educación tradicional donde el estudiante es un pasivo receptor, a la educación de alta calidad donde el estudiante participa activamente los procesos de aprendizaje, situación para la cual debe estar dispuesto emocionalmente.

Debemos preparar nuestros estudiantes no solo en lo académico e intelectual, sino en todas sus aristas, tal como se propone en los pilares de Educación (los cuatro aprendizajes fundamentales: Aprender a Ser; Aprender a Conocer; Aprender a Convivir y Aprender a Hacer) aunados a los actualmente propuestos, dichos saberes cada vez más llevados a la práctica.

La formación del estudiante debe centrarse profundamente en la concepción de un ser humano con las habilidades requeridas no solo para el éxito académico, sino para los retos que les platea la vida. Asimismo, es fundamental conocer el mundo emocional interno del estudiante, reconocerle como ser emocional y todo lo que ello conlleva.

En este sentido es oportuno reseñar las habilidades sugeridas por el Tony Wagner (2010) ${ }^{28}$, señalando los retos de la educación del siglo XXI y XXII:

\section{Resume las siguientes habilidades:}

1. Promover el pensamiento crítico y la capacidad de resolver problemas.

2. Espíritu colaborativo y liderazgo por influencia (en lugar de por autoridad.)

3. Capacidad para acceder y procesar la información disponible.

28 Tony Wagner, (2010) Habilidades para el estudiante del siglo XXI. Tomado de Habilidades del siglo XXI y su impacto en la Practica Áulica. Itinerario Transformando la Educación. Red Qualitas. Microsoft. (P.44) 
4. Capacidad de adaptación y rapidez (flexibilidad, adaptabilidad para tener éxito).

5. Iniciativa y un espíritu emprendedor.

6. Comunicación oral y escrita efectiva, para desarrollar argumentos y opiniones.

7. Curiosidad e imaginación de donde nace la innovación. (P.44)

Este es un desafío que no solo tiene la Educación Popular, sino la educación en general en todo el mundo. Es necesario la adecuación y formación tecnológica, humana, científica y emocional entre otras. No cabe duda que la educación es un reto, un desafío, lo cual también es emocionante. En palabras de Edgar Morín(1999) ${ }^{29}$ también expone sobre los desafíos que supone la educación actualmente:

Se tendrían que enseñar principios de estrategia que permitan afrontar los riesgos, lo inesperado, lo incierto, y modificar su desarrollo en virtud de las informaciones adquiridas en el camino. Es necesario aprender a navegar en un océano de incertidumbres a través de archipiélagos de certeza.(p.3)

Edgar Morin 1999

\section{El rol del Educador Popular}

Los educadores populares son esencialmente transformadores, tal y como se ha mencionado, las trasformaciones nacen desde la persona, desde el ser. En este sentido el educador al fortalecer en su propia vida los componentes de la inteligencia emocional, hará de su práctica pedagógica un quehacer más fructífero, asimismo se encontrará en mejor posición para estimular en los estudiantes dichos componentes, al tiempo que se genera en los centros educativos espacios para la calidez y el aprendizaje integral.

Fe y Alegría se ha caracterizado por ser fraternal en todos sus

29 Edgar Morín (1999) Los siete saberes necesarios para la educación del futuro. UNESCO Francia p. 3 
ambientes, rompiendo con el paradigma tradicional de distancia entre sus colaboradores, el educador empoderado desde la inteligencia emocional expandirá su conciencia y plenitud, experimentando su propia transformación personal.

¿Cómo poner en práctica un programa de educación emocional?

Existen múltiples maneras de colocar en práctica y estimular la inteligencia emocional en los entornos de aprendizaje, sea por medio de un programa específico o en la práctica diaria.

$\checkmark$ Formación de los docentes.

$\checkmark$ Escuela para padres.

$\checkmark$ En las asignaturas, proyectos de aula y de aprendizaje.

$\checkmark$ Educación ciudadana más allá de lo convencional.

$\checkmark$ Los departamentos y coordinaciones de orientación y afines. BEI -DECE

BEl: Bienestar Educativo Integral

\section{Algunas situaciones cotidianas de aplicabilidad de la inteligencia emocional}

$\checkmark$ Enfrentar miedos

$\checkmark$ Lidiar con rupturas emocional

$\checkmark$ Manejar la ira

$\checkmark$ Manejar la ansiedad

$\checkmark$ Manejar la tristeza

$\checkmark$ Mantener relaciones sanas

$\checkmark$ Superar el Bullying.

$\checkmark$ Combatir y evitar el Mobbing y combatir Ciberacoso. 
$\checkmark$ Estimular la Resiliencia.

$\checkmark$ Crecimiento personal.

$\checkmark$ Fortalecer la voluntad.

$\checkmark$ Para la toma de decisiones.

$\checkmark$ Otras aplicaciones.

Finalmente, la Educación Popular y la inteligencia emocional van de la mano, estrechando lazos para el fortalecimiento y la edificación de seres humanos integrales, felices, plenos. En un entorno de aprendizaje y convivencia cálido, donde se viven emociones sanas. Encontrando respaldo y fraternidad en sus educadores y compañeros. Asimismo, con educadores felices y satisfechos, sanos emocionalmente, asertivos y resilientes, que se transforman a sí mismos para transformar su entorno.

\section{Conclusiones}

A fin de lograr la exploración de la inteligencia emocional y la educación popular como claves para la transformación educativa se precisó en primer lugar las bases de la inteligencia emocional en la práctica educativa, se identificó los principios de la educación popular asociados a la educación del ser y las emociones para luego explicarse la importancia de la inteligencia emocional en la educación popular y su articulación.

Al identifica los principios de la inteligencia emocional, estos le permiten al educador alfabetizar emocionalmente a sus estudiantes, quedando claro que en primer momento se requiere de una capacitación del educador, como líder y guía del aula, para luego poder formar en sus estudiantes la tan importante conciencia emocional.

Asimismo, el rol del educador popular y del estudiante son claves en la inteligencia emocional, tanto para la educación popular como para la transformación de los contextos sociales. Se visualiza también la importancia de la formación a la familia al respecto y la vinculación de todos los actores del hecho educativo en un ambiente cada vez mas cálido, fraternal y humano. 


\section{Referencias Bibliográficas}

Edgar Morín (1999) Los siete saberes necesarios para la educación del futuro. UNESCO. Francia.

Fe y Alegría Ecuador. (2016). Horizonte Pedagógico Pastoral.

Gómez, G. Héctor G. (2013). Un mapa en el laberinto. La felicidad es un estado mental y puede ser aprendido. Editorial Singularidad.

Lazcano, J. s.j. (2005). Palabras de Fe y Alegría. Citas inspiradoras del Padre José María Vélaz. Caracas: Federación Internacional Fe y Alegría.

Libertador Simón Bolívar. (1824). Palabras del Libertador a Simón Rodríguez desde Perú.

Maestro J (2009) Regálate liderazgo, una estrategia para desarrollar los talentos emocionales del Líder. Editorial Porfit.

Sambrano, J. (2014) Inteligencia Emocional. Guía práctica para alfabetizar nuestras emociones. Editorial ALFA. Venezuela.

Tony Wagner, Habilidades para el estudiante del siglo XXI. (2017) Tomado de Habilidades del siglo XXI y su impacto en la Práctica Áulica. Itinerario Transformando la Educación. Red Qualitas. Microsoft.

Pérez Esclarín Antonio. (2004). Colección programa internacional de formación de Educadores populares. La educación popular y su pedagogía. Editorial Federación Internacional de Fe y Alegría. Venezuela. 